\title{
ENVIRONMENTAL SUSTAINABILITY REPORT AND ITS ACHIEVEMENT: TOWARDS THAI-CONSTRUCTION SECTOR
}

\author{
Neungruthai Petcharat, Faculty of Business Management Studies, Gulf College, Oman \\ Phanthipa Srinammuang, Kasetsart University, Bangkok, Thailand
}

dx.doi.org/10.18374/RBR-19-2.2

\begin{abstract}
This study evaluates the achievement of environmental sustainability reports produced of Thai construction companies under the mandatory reporting regime and concerns about environmental impacts of the construction industry in Thailand, as it was necessitated emphasis on business practices and eco-efficiency. Data was collected through a review of annual reports of sixty-five construction companies listed on the Thailand Stock Exchange. Environmental improvement activities identified in the reports are analysed and the quality of the disclosures were evaluated against the Global Reporting Initiative (GRI) framework and qualitative characteristics used as a benchmark to assess traditional financial reports. The results indicate that while the mandatory reporting regime on the Thai construction sector has fostered the quantity of disclosures in annual reports, wide variations still exist in the information disclosed in the reports owing to management's considerable reporting discretion. The reporting practices show room for improvement with respect to enhancing informativeness of environmental disclosures and achievement of environmental improvement to stakeholders
\end{abstract}

Keywords: Environmental information, Environmental sustainability reporting, GRI guidelines 